\title{
Exploring the effect of an augmented reality literacy programme for reading and spelling difficulties for children diagnosed with ADHD
}

\author{
Crispino Tosto $^{1} \cdot$ Tomonori Hasegawa $^{2} \cdot$ Eleni Mangina $^{2} \cdot$ Antonella Chifari $^{1} \cdot$ Rita Treacy $^{3} \cdot$ Gianluca Merlo $^{1}$. \\ Giuseppe Chiazzese ${ }^{1}$ (1)
}

Received: 23 February 2019 / Accepted: 5 November 2020 / Published online: 24 November 2020

(c) The Author(s) 2020

\begin{abstract}
Children diagnosed with attention deficit hyperactivity disorder (ADHD) experience a variety of difficulties related to three primary symptoms: hyperactivity, inattention and impulsivity. The most common type of ADHD has a combination of all three symptom areas. These core symptoms may negatively impact the academic and social performance of children throughout their school life. The AHA (ADHD-Augmented) project focused specifically on the impact of digital technologies' intervention on literacy skills of children that participated in the pilot study and were diagnosed with ADHD prior to the intervention. Existing research has shown that augmented reality (AR) can improve academic outcomes by stimulating pupils' attention. AHA project aimed at implementing an evidence-based intervention to improve ADHD children's reading and spelling abilities through the enhancement of an existing literacy programme with AR functionality. The present paper reports preliminary findings of the pilot study aimed at evaluating the effectiveness of the AHA system in promoting the acquisition of literacy skills in a sample of children diagnosed with ADHD compared to the literacy programme as usual. Background information on the main characteristics and difficulties related to the teaching and learning process associated with children diagnosed with ADHD are first introduced; the design and methodology of the AHA project intervention are also described. The preliminary findings have shown that AHA project succeeded in delivering an AR solution within an existing online literacy programme, which integrates a set of specific technologies and supports interactive educational content, services, assessment, and feedback.
\end{abstract}

Keywords ADHD $\cdot$ Augmented reality $\cdot$ Literacy programme $\cdot$ Behavioural monitoring $\cdot$ Reading and spelling difficulties

\section{Introduction}

A diagnosis of attention deficit hyperactivity disorder (ADHD) in childhood is typically associated with low levels of engagement with educational tasks, poor academic performance, and specific learning difficulties (SLDs) (e.g. dyslexia and dysgraphia) in a number of cases. In this regard, the ADHD-augmented (AHA) pilot project aimed at developing the AHA system as an educational tool integrating augmented reality (AR) content into an existing effective

Giuseppe Chiazzese

giuseppe.chiazzese@itd.cnr.it

1 Istituto per le Tecnologie Didattiche, Consiglio Nazionale delle Ricerche, Palermo, Italy

2 University College Dublin, Dublin, Ireland

3 WordsWorth Learning Limited, Dublin, Ireland literacy programme to address ADHD children's reading and spelling difficulties while supporting their engagement with the learning activities. Specifically, it was hypothesized that AR content would further strengthen the effect of the literacy programme on children's learning outcome through its positive impact on their engagement with the intervention activities.

The main aim of the present paper is to report preliminary findings of the pilot study on the effectiveness of the AHA system in promoting the acquisition of literacy skills in a sample of children diagnosed with ADHD. The paper first introduces readers to research evidence that guided the project conception, a detailed description of the AHA system, and the full research protocol followed for the evaluation purposes of the pilot. 


\subsection{Childhood ADHD: main characteristics and related scholastic difficulties}

ADHD is a neurodevelopmental disorder that usually manifests in childhood and whose worldwide estimated community prevalence fluctuates between 2 and 7\% (Sayal et al. 2018). In Ireland, there are 509,652 children enrolled in 3305 primary schools (Junior Infants up to including 6th class); out of this estimate, 3-5\% have ADHD (OECD 2011). The disorder is characterized by behavioural expressions of inattention, disorganization, and/or hyperactivity-impulsivity that are recognized as not consistent with a child's age or developmental level and affecting his/her psychosocial functioning (American Psychiatric Association 2013). Moreover, a significant portion of children diagnosed with ADHD also present with comorbid diagnoses of SLDs, such as reading and spelling difficulties (dyslexia), and writing difficulties such as dysgraphia (DuPaul et al. 2013).

According to Barkley (1997), the neurodevelopmental deficit is hypothesized to affect executive functions and results in impaired non-verbal working memory, delayed internalization of speech (verbal working memory), immature self-regulation of affects, motivation, and arousal. Several studies have shown that children with ADHD demonstrate lower self-expectations, less persistence and enjoyment, and more discouragement when dealing with academic tasks, and a preference for easy rather than challenging work as a consequence of the specific neurodevelopmental deficit (Carlson et al. 2002; Hoza et al. 2001). In other words, children with ADHD typically show relevant levels of inattentive behaviour and their academic engagement has been found to be significantly lower than that of their typically developing peers, with a consequent reduction in productivity and opportunities for learning (Kofler et al. 2010).

More specifically, it has been assumed that a motivational deficit may explain the reported poor levels of engagement with the task among children with ADHD (Luman et al. 2005). In this regard, literature has already provided findings confirming that low levels of motivation, in children presenting with ADHD symptoms, predict worst academic achievements via its relationship with academic engagement (Demaray and Jenkins 2011; Volpe et al. 2006). Deficits in working memory, specifically in central executive processing and storage/rehearsal capacity, account for higher levels of inattentive behaviour of children with ADHD at lower cognitive loads when compared to typically developing peers (Kofler et al. 2010). As a consequence, a significant percentage of students with ADHD present off-task or offrule behaviours which require specific learning strategies. Given their poor self-regulation and deficient working memory, children with ADHD may require coaxing and coaching from external sources such as teachers, parents, peers, visual cues, and/or technology. So, it is possible to hypothesize that when children are engaged in cognitive stimulus that require a great amount of attention until completion of the goal, as in the case of reading and spelling activities, adding interest and novelty through augmented representations of the vocabulary chunks may help students boost their learning outcomes acting on their concentration and working memory processes (Garzón et al. 2019). Examples of these cues are written rules, visual routines, visual learning prompts, use of colours, graphic supports, augmented objects, and flash cards among others. Moreover, these supports seem to allow students with ADHD to hold information in mind, while they work with bits and pieces of information and use that information to complete a task (Daley and Birchwood 2010). Given that ADHD off-task behaviours are stimulated by boring learning stimuli and the use of appropriate stimulation affects the brain's ability to focus and sustains performance, the general aim of the AHA application, described below, is to improve literacy outcomes through the use of AR content superimposed onto an effective literacy programme.

\subsection{Related work}

The present section aims to introduce research studies on the use of AR technology in educational settings. AR represents an implementation of virtual environments known as virtual reality; its specificity lies on virtual objects, developed by computers that can be superimposed onto physical objects in real time (Zhou et al. 2008). In educational settings, AR offers several educational solutions that may support teaching and learning processes (Billinghurst and Duenser 2012; Radu 2014). Specifically, it provides useful explorative experiences of educational content through the combination of real and virtual information; in fact, the student lives an augmented learning experience where a manipulation of multimedial virtual objects combine different media content like animation, sound tracks, images, and videos providing a new form of multimedia learning (Mayer 2001).

AR solutions can strengthen students' academic outcomes compared to traditional methods (Ozdemir et al. 2018). In addition to proved learning gains, research has highlighted several advantages related to the use of AR systems in educational system that may at least partially account for better academic outcomes, the most relevant being an increase in learners' motivation, sensory engagement, memory retention, and satisfaction with the learning experience (Garzón et al. 2019; Saltan and Arslan 2017). With regard to language education, literature has provided evidence regarding the effectiveness of integrating AR into learning activities in terms of enhancement of students' reading comprehension and acquisition of writing skills (Billinghurst et al. 2001; Vate-U-Lan 2012). More specifically, AR educational 
solutions have been found to strengthen learners' vocabulary retention and spelling skills (Khoshnevisan 2018). A recent AR system has been developed for supporting the acquisition of children's reading and spelling abilities such as phonological awareness and knowledge of the alphabetic principle (Fan et al. 2018). The system provides a combination of augmented dynamic color cues and three-dimensional physical lowercase letters that is assumed to support children's learning by stimulating their attention and providing interactive feedback on their actions.

With specific regard to children diagnosed with ADHD, a study among non-English children presenting with reading difficulties (Lin et al. 2016) showed a positive effect of an AR literacy intervention in strengthening learners' reading ability and their performance in word recognition tasks. A more recent study (Avila-Pesantez et al. 2018) described the development of an AR serious game to train selective and focused attention in children diagnosed with ADHD. The preliminary findings of this study suggest the effectiveness of AR solutions in increasing children's concentration and reducing their frustration during the solution of problemsolving activities. Similarly, another study (Vahabzadeh et al. 2018) reported initial evidence on the effectiveness of AR solutions in reducing ADHD-related symptoms, such as hyperactivity, inattention, and impulsivity, in school-aged children diagnosed with autism spectrum disorder. Specifically, children were asked to use AR smartglasses during social and behavioural therapeutic modules and showed a decrease in ADHD-related symptoms over time. Overall, these findings suggest that AR solutions may be effectively applied to provide tailored solutions for reading and spelling difficulties in children presenting with ADHD, assuming that such solutions can address learning outcomes also via its impact on inattentive behaviour.

\section{The AHA system}

The AHA (ADHD-Augmented) project ${ }^{1}$ developed the AHA system as an integrated web-based AR learning environment on the basis of theoretical considerations and evidence provided by existing research. The AHA system aims at implementing an evidence-based intervention to quantitatively and qualitatively study the effect of AR on reading and spelling performances and levels of engagement with tasks of primary school pupils diagnosed with ADHD in a learning environment (Chiazzese et al. 2018).

The AHA system has been realised integrating the WordsWorthLearning@ (WWL) Programme, ${ }^{2}$ a web-based

\footnotetext{
$\overline{1}$ http://aha.ucd.ie.

2 https://www.wordsworthlearning.com.
}

educational tool aimed at strengthening English literacy, with a series of AR objects (see Sect. 2.2 for a detailed description). WordsWorthLearning is a web-based literacy programme initially designed to remediate reading and spelling problems, such as dyslexia (Treacy 2017). The system originally consisted of a paper-based literacy programme, the content of which was developed over years of clinical private practice. It was later consolidated in a more affordable digital version that has the advantage of supporting the individual learning in different educational settings. The programme currently consists of several video tutorials and interactive exercises organized into seven hierarchical and progressive levels, from basic speech sounds to complex multisyllabic words, that learners should complete in order. Users are also equipped with the two Vowel and Consonant charts that are used throughout the programme to support the learning of the associations between letters and speech sounds. The WWL programme starts by training learners' phonemic awareness and progresses to teaching phonological awareness, defined as the ability to analyse words into their basic speech sounds, to combine speech sounds properly and to identify rhyme and alliteration. To reach this aim, the programme systematically teaches and trains a set of basic rules and integrates step by step more complex rules to reinforce cognitive skills required for word analysis. It also contains a total of twelve questionnaires that users are required to complete to monitor their learning progress at the end of each level or on multiple occasions within the same level when required. Overall, the programme structure was maintained for the purposes of the AHA system.

Additionally, several facilities for monitoring users' engagement and outcomes has been implemented through the adaptation of the Web Health Application for ADHD Monitoring (WHAAM), ${ }^{3}$ a web-based service for the behavioural monitoring of children diagnosed with ADHD. The AHA system primarily provides a dashboard where students' progress through WWL modules and levels can be monitored. In fact, a log of each student's activity and progression (e.g. multiple-choice questionnaire scores) on the WWL programme is collected on an anonymized basis. At the same time, the AHA provides a dashboard which enables parents and teachers (the observers pre-assigned to the students for the pilot purposes) to monitor their students' WWL activity and progression through the regularly synchronized database, as well as to register observation data based on their children's off-task behaviours over the course of the intervention. Such data collected and combined over time provides a basis for further comprehensive data analysis to characterize participants' performance. Figure 1 shows the AHA system interface composed by two sides: (1) the

\footnotetext{
3 https://app.whaamproject.eu/en/index.php.
} 
1) The learning interface dashboard for Students
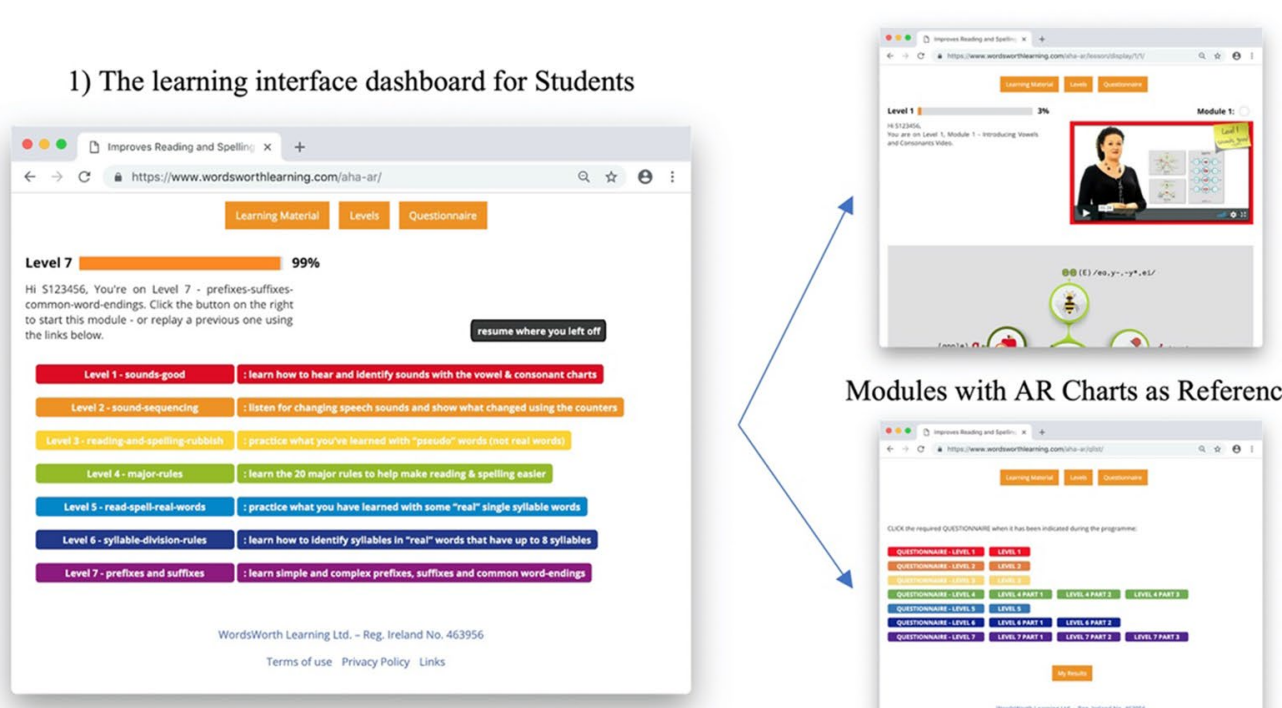

Modules with AR Charts as Reference
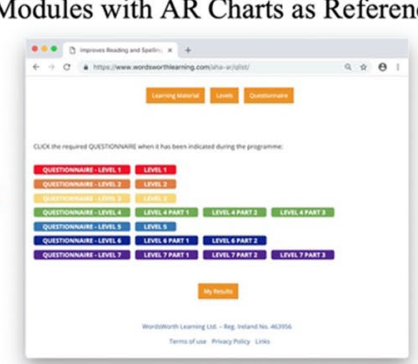

Questionnaires for Testing Comprehension

2) The monitoring interface (dashboard for teachers/parents).
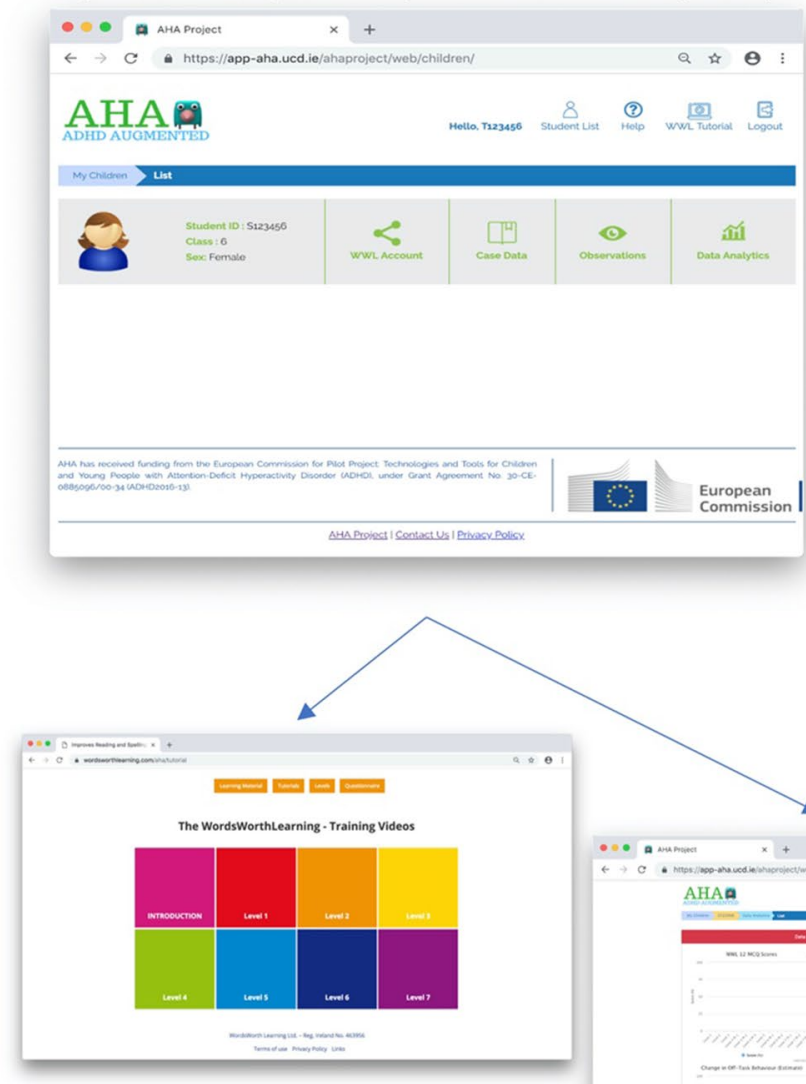

WWL Tutorial (Teachers only)

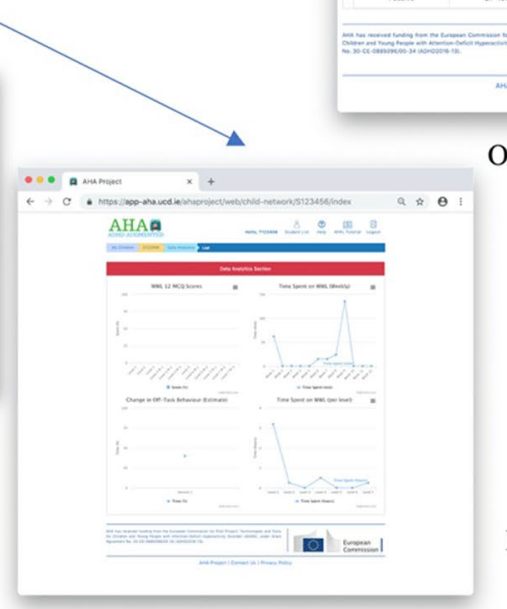

Data analytics

Fig. 1 AHA system 
learning interface (dashboard for students); (2) the monitoring interface (dashboard for teachers/parents). The system is web-based and therefore no further application has to be installed and users can gain access regardless of the devices as long as they are equipped with up-to-date web browsers.

The AHA learning interface allows children with ADHD to access the WWL programme with AR content (accessible from desktop or mobile phone with a camera) designed to attract students' engagement and thus facilitate the training of their reading and spelling skills. In the context of the AHA pilot, the WWL system interface has been powered with the addition of AR objects that would hopefully enhance the interaction of users with the learning environment.

On the other hand, the monitoring interface has been implemented to allow teachers and parents to follow the progress of their pupils during the interaction with the learning programme and actively participate in the evaluation process. This allows teachers and parents to access the facilities devoted to the behavioural monitoring and periodic evaluation of their children's learning progress. These facilities are described in detail later in the manuscript (see Sect. 3.1).

\subsection{The development of AR objects in the AHA system}

A key concept in the definition of the AHA system design is the notion of software architecture. A widely recognized concept to handle the complexity of systems is to divide the problem into several parts. Following the application of this concept to software architectures, we identified three main parts potentially constituting the architecture of the AHA software: (1) an AR webpage to handle the display, interaction, and animation of AR content; (2) an integration between this Web-AR software and the AHA live website; (3) a Content Management Tool (CTM).

As already pointed out, the AHA client interface provides WWL-AR learning content through the AHA training intervention interface, along with the AHA monitoring interface functionalities. WWL content has been advanced with WebAR through the utilization of A-frames with Three.JS ${ }^{4}$ and AR.js. ${ }^{5}$ AR.js made the 3D content displayed in AR on the users' digital devices.

The interaction and triggering of the AR content has been accomplished with the creation of an accompanying marker. This content takes the form of 3D objects, video, pictures, text, and sounds.

\footnotetext{
${ }^{4}$ https://en.wikipedia.org/wiki/Three.js.

${ }^{5}$ https://aframe.io/blog/arjs/.
}

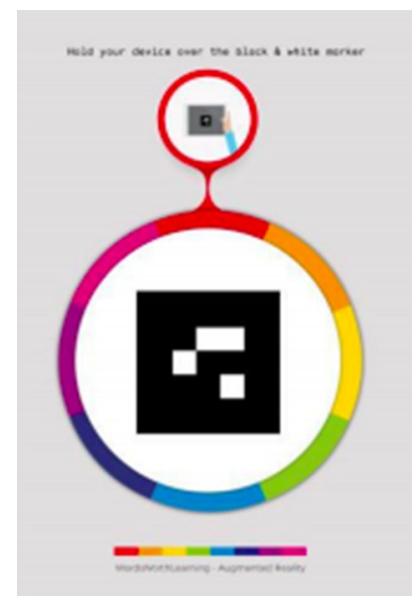

Fig. 2 AHA AR marker

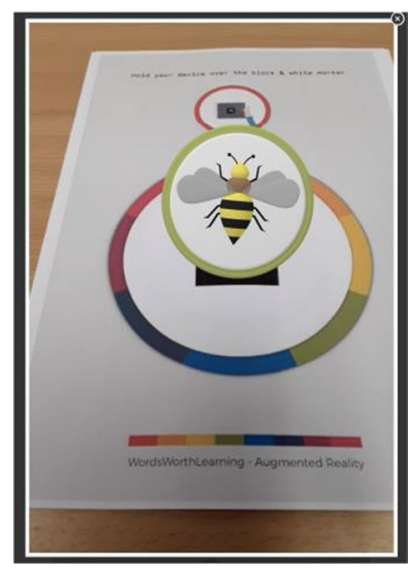

Fig. 3 Demo of a 3D coin

\subsection{The AHA AR objects}

Three-dimensional learning objects (3DLOs) are learning objects that have a three-dimensional design and also have interactive features that focus on promoting the "learning by doing" attitude (Mangina 2017). In the case of distance learning, users can usually view hundreds of teaching videos and the problem is that users are mere spectators. They do not interact with the teacher, and their activities are all done through watching and listening. Alternatively, 3DLOs can provide an additional level of multi-sensory learning experience by introducing touch through AR.

For the AHA Project, a total of 90 AR objects were implemented in the different levels of the WWL learning programme as follows: 


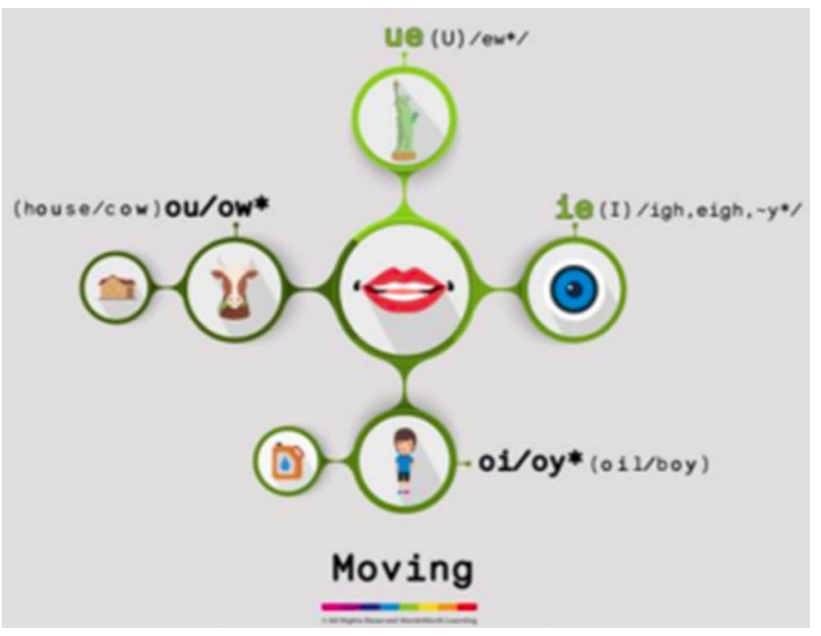

Fig. 4 Example of augmented reality vowels chart

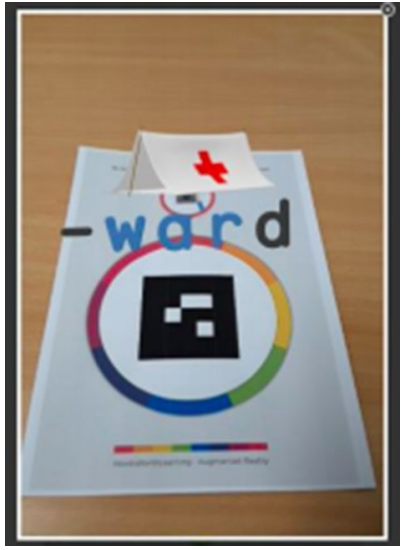

Fig. 5 Demo of an AR object for flashcards

- $1 A R-W W L$ marker. The marker allows the user to visualize the AR object using their mobile device (Fig. 2). The child can click on a specific AR object in the learning environment and the camera is activated by holding their mobile device with the camera over the marker to see the AR object displayed.

- 60 2D/3D AR animated coins were created for the WWL consonant and vowel charts and also the literacy rules (Figs. 3 and 4). The Vowel and Consonant charts ${ }^{6}$ introduce AR elements to bring to life 3D examples of letters and their corresponding sounds. Clicking on one of the vowel/consonant pictures (icons) will open the camera. Moreover, AR has been developed to enhance learning

\footnotetext{
6 The Vowel and Consonant charts are used throughout the WWL programme and are designed to show the link between speech sounds (or phonemes) with their letter representations.
}

for several literacy rules, such as those related to the use of prefixes and suffixes. If the child is using a mobile device, he/she can point the camera at the provided WWL marker to view the AR content. In the case of a computer with a screen and a front camera, the student can lift the marker to the camera to visualize the object on the screen.

- 30 AR objects for flashcards. The AR flashcards are similar to the AR vowel and consonant charts but their functionality is reduced; they are introduced to enhance one particular lesson. Certain pages have a "View in AR" button and by clicking this the camera on the device opens. The user can scan the marker to visualize the AR content. The virtual model plays an animation when the marker is detected (Fig. 5); however, unlike the vowel/ consonant content, the animation does not include sound and does not rotate, because rotation would distort the direction and order of letters and confuse the student.

\section{The AHA pilot and its research design}

Aims of the pilot have been setted to evaluate: (1) the incremental effect of embedded AR content on children's reading and spelling abilities, and (2) the engagement with the proposed activities. For this purpose, a pre- and posttest design (Kazdin 2003) has been followed: children were quasi-randomly assigned to two intervention groups (WWL programme enhanced with AR (WWL-AR) versus traditional WWL programme only) and one control group (without any access to WWL programme); the assignment was random for the majority of participants except in a few cases where children from the same schools were for convenience assigned to one condition. Following the recruitment process, a total of 117 pupils were enrolled based on the following criteria: (1) at the time of recruitment to be in either 3rd, 4th or 5th Class in the primary school system in Ireland (aged from 8-9 to 11-12 years); (2) to have a diagnosis of ADHD; (3) to have an estimated functioning in the average range of I.Q.; (4) to have availability of a broadband connection at home/in school and laptops/tablets with webbrowsers to access the learning platform. Figure 6 presents a description of students, parents and teachers' expected activities during the involvement in the pilot.

Participants in the pilot come from 22 Irish counties as shown in Fig. 7. Participants are roughly equally distributed across the grades of 4th, 5th, 6th (except for two exceptional cases in the 3rd grade). Participants from Dublin, Wicklow, or Galway account for nearly a half of the entire sample (57 students; 49\%). The majority of them (112 students; 96\%) responded that Ireland is their country of origin, while the remaining part named other countries. Most of them are male (94 participants; 80\%). 


\begin{tabular}{|c|c|c|c|}
\hline & $\begin{array}{c}\text { Group } 1 \\
\text { AHA intervention } \\
\text { (AR-enhanced WWL) }\end{array}$ & $\begin{array}{l}\text { Group } 2 \\
\text { WWL intervention } \\
\text { (traditional WWL) }\end{array}$ & $\begin{array}{c}\text { Group } 3 \\
\text { Control } \\
\text { (without intervention) }\end{array}$ \\
\hline $\begin{array}{l}\text { Student } \\
\text { Users }\end{array}$ & $\begin{array}{l}+ \text { Access to WWL+AR Programme } \\
\text { + Assessment from Speech } \\
\text { Language Therapist (Pre/Post) } \\
\text { + Survey questionnaire (Post) }\end{array}$ & $\begin{array}{l}\text { Access to WWL Programme } \\
\text { + Assessment from Speech } \\
\text { Language Therapist (Pre/Post) } \\
\text { - Survey questionnaire (Post) }\end{array}$ & $\begin{array}{l}+ \text { No access to WWL Programme } \\
+ \text { Assessment from Speech } \\
\text { Language Therapist (Pre/Post) } \\
+ \text { No survey questionnaire }\end{array}$ \\
\hline $\begin{array}{l}\text { Parent } \\
\text { Users }\end{array}$ & $\begin{array}{l}\text { Access to AHA Dashboard } \\
\text { \& Access to WWL+AR Programme } \\
\text { \& Survey questionnaire (Pre/Post) }\end{array}$ & $\begin{array}{l}\text { Access to AHA Dashboard } \\
\text { Access to WWL Programme } \\
\text { \& Survey questionnaire (Pre/Post) }\end{array}$ & $\begin{array}{l}\text { No access to AHA Dashboard } \\
+\quad \text { No access to WWL Programme } \\
+ \text { No survey questionnaire }\end{array}$ \\
\hline $\begin{array}{l}\text { Teacher } \\
\text { Users }\end{array}$ & $\begin{array}{l}\text { Access to AHA Dashboard } \\
\text { \& Access to WWL+AR Programme } \\
\text { \& Access to WWL+AR Training } \\
\text { \& Survey questionnaire (Pre/Post) }\end{array}$ & $\begin{array}{l}\text { Access to AHA Dashboard } \\
\text { Access to WWL Programme } \\
\text { \& Access to WWL Training } \\
\text { \& Survey questionnaire (Pre/Post) }\end{array}$ & $\begin{array}{l}\text { No access to AHA Dashboard } \\
\text { No access to WWL Programme } \\
\text { \&o survey questionnaire }\end{array}$ \\
\hline
\end{tabular}

Fig. 6 Distribution of users' expected activities between groups

Prior to the beginning of the pilot, a detailed case-history form was given to parents, in order to collect a wide variety of information about the students, comprising family details, pregnancy and birth history, developmental history, functional history, medical history, social and behavioural history, family history, educational history, executive function, academic performance, and assessment treatment history. Of all variables collected, we chose to report a selection on the basis of their relevance in describing the sample characteristics (Table 1). Most of the children participating in the project were reported to receive learning and psychological and psychiatric support; in addition, a half of enrolled pupils were reported to take ADHD-related medication.

Finally, teachers and parents of the students assigned to the two intervention groups were asked whether they knew about AR prior to the intervention. A total of 123 teachers and parents responded. In this respect, no significant difference between the teachers and parents was apparent. Overall, the majority (84\%) of them knew the correct definition of AR while others tended to confuse it with the objective of this pilot project.

\subsection{Measures of children's literacy and methodology for the behavioural observation during the pilot}

For the evaluation purposes of the pilot, the Neale Analysis of Reading Ability (NARA-II; Neale 1997) and the Vernon Graded Word Spelling Test (Vernon 2006) were chosen to assess participants' reading and spelling abilities respectively in the pre- and post-test administrations. Moreover, a measure of participating children's learning outcome was derived from their performance on the WWL questionnaires. Specifically, at the completion of each level of the WWL programme, users are required to fill in a questionnaire evaluating their acquisition of the literacy skills promoted by the learning materials included in the level. As a consequence, the questionnaires provides measures of acquired literacy skills from the ability to correctly link speech sounds (phonemes) with their letter representations (taught at level 1) to the correct use of prefixes and two-syllable and complex suffixes, and common word endings (see Mangina, 2018 for an overview of literacy skills taught at each level). There are seven levels within the WWL literacy skills intervention; however, children with good literacy skills are not required to complete level 2. The WWL programme contains 12 questionnaires, one per level, with the exception of levels 4,6 , and 7 , which have 3,2 , and 3 questionnaires, respectively, to be completed at scheduled intervals while working through the levels.

On the other hand, a detailed description of the methodology chosen to derive a reliable measure of children's engagement with the WWL activities (WWL-AR and WWL) is as follows. The Direct Behaviour Rating approach (Chafouleas et al. 2005, 2009) was adopted as the guiding methodology to longitudinally measure children's off-task behaviour during their interactions with WWL (alone and augmented). According to the definition provided by Shapiro (1996), off-task behaviours were operationalized as motor, verbal or passive activities that cannot be directly connected with the assigned WWL task. Specifically, Off-Task Motor (OFT$\mathrm{M})$ refers to times when a student is performing any type of motor activity that is not related to and clearly interferes with the completion of the assigned task (e.g. fidgeting in one's seat). Off-Task Verbal (OFT-V) refers to verbalizations that are not authorized or anyway related to the WWL task. Finally, Off-Task Passive (OFT-P) implies occasions when the pupil is passively not attending to the assigned activity 
Fig. 7 Geographical origin of students participating in the pilot research (Map: @OpenStreetMap contributors)

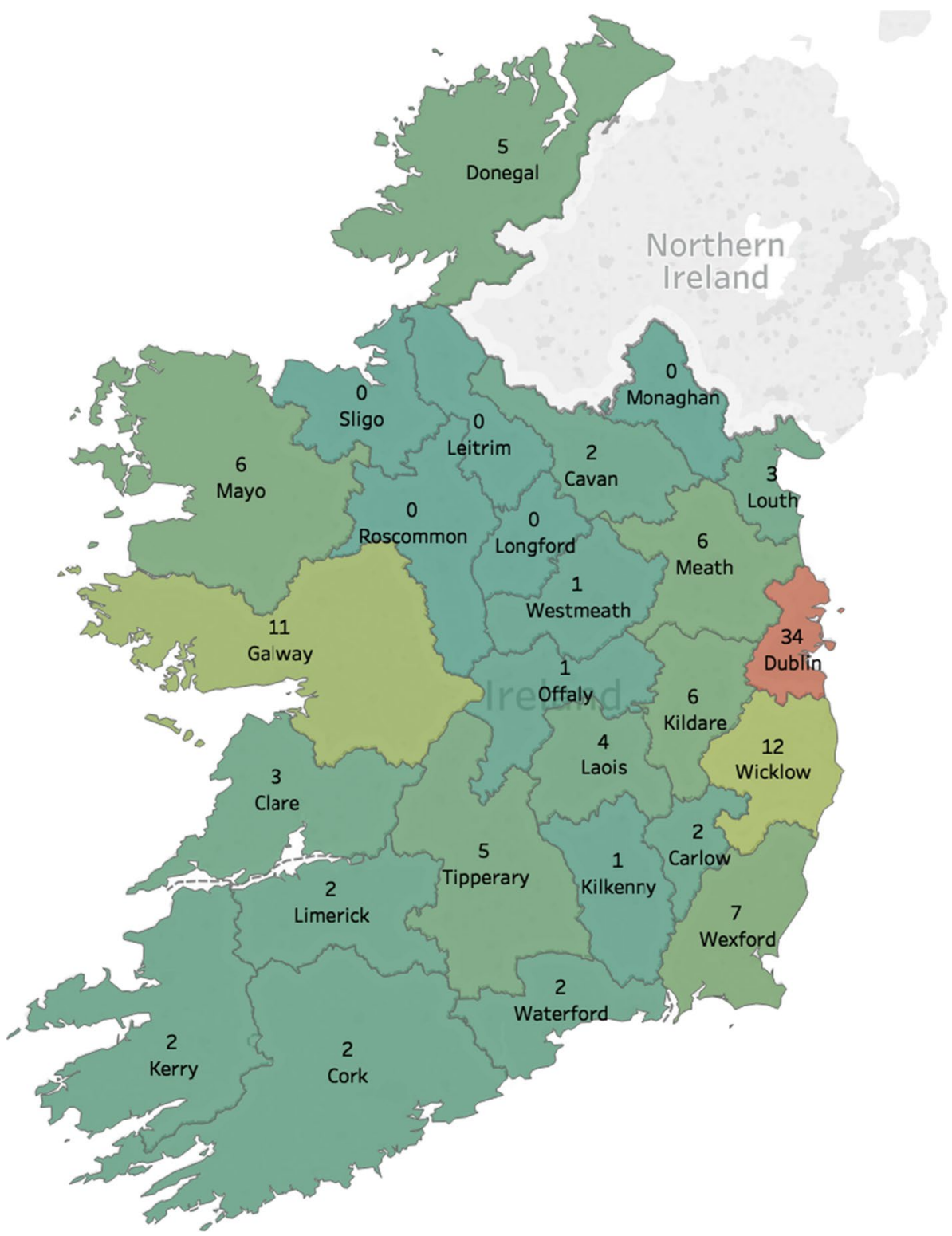

for a time interval of at least three consecutive seconds (e.g. sitting in an unassigned activity).

Parents and teachers of each child participating in the pilot (WWL-AR and WWL groups) were asked to act as observers of their pupils' activities during the intervention. Before beginning participation, parents and teachers were asked to carefully read the "AHA Teacher and Parent Guide" (Mangina 2018). The guide contains a description of the AHA pilot and system, and detailed instructions on the WWL programme, use of AR objects and of the designed tool for observing and rating children's off-task behaviour. Specifically, as observers of their children's activity, teachers and parents were asked to rate on a 6-point Likert-type scale the occurrence of off-task behaviour in terms of percentage of time of the entire observation period. They were instructed to rate first the overall percentage of time the child was off-task and subsequently provide ratings of motor, verbal, and passive off-task behaviours (Chafouleas et al. 2009). Each child in both intervention groups was observed during each WWL session for $15 \mathrm{~min}$. At the end of the observation interval, the observer had to rate the occurrence of the off-task behaviour using the slider interface tool specifically developed for the AHA application (as shown in Fig. 8).

Beyond the pilot research purpose, the AHA application has also been designed to create a shared web-based virtual space for parents, teachers, and experts close to the child. The application allows significant adults involved in the potential intervention to monitor over time their child's learning progress and engagement using facilities specifically realized for this purpose within their user's dashboard. Such facilities include line graphs showing the student's progress through the consecutive levels of the WWL 
Table 1 Selected variables describing sample characteristics

\begin{tabular}{lcr}
\hline Variable & $N$ & $\%$ \\
\hline Difficulty staying focused & 117 & 100 \\
Receive learning support & 113 & 97 \\
Weak organisational skills & 113 & 97 \\
Do technology activities & 113 & 97 \\
Weak planning & 107 & 91 \\
Psychology professional attended & 107 & 91 \\
Difficulty emotion control & 105 & 90 \\
Mainstream school & 105 & 90 \\
Psychiatry professional attended & 104 & 89 \\
Weak working memory & 101 & 86 \\
Hyperactivity & 77 & 66 \\
ADHD-related medication & 54 & 46 \\
Comorbidities & & \\
Dyspraxia & 85 & 73 \\
Dyslexia & 78 & 67 \\
Language difficulties & 50 & 43 \\
Speech difficulties & 42 & 36 \\
Autism spectrum disorder & 31 & 26 \\
ADHD family diagnosis & & 25 \\
Siblings & 29 & 15 \\
Parents & 17 & \\
\hline ADHD Atention deficit & & \\
\hline
\end{tabular}

$A D H D$ Attention deficit hyperactivity disorder

intervention, as measured by the questionnaire administered at the end of each level. Additional line graphs show the total amount of time spent by the pupil in performing WWL activities per level, and the time weekly spent on the activities. Finally, a line graph summarizes for each session the time percentages the pupil spent in general, motor, verbal, and passive off-task behaviours (Fig. 9).

Thus, the AHA application supports data collection and provides on-fly statistical evidence to significant adults involved in the educational process.

\section{Pilot and intervention procedures}

The pilot was conducted during the period between June 2018 and June 2019, and Fig. 10 shows the steps followed for its implementation.

Once recruited, students were assigned to the predefined experimental conditions (WWL-AR, WWL, and control) and went through the pre-test assessment during June to September 2018 and were tested again during the last 3 months of the pilot (from April to June 2019). The children were assessed primarily by Ms Rita Treacy (WordsworthLearning Ltd.). All children assessed in the WordsworthLearning office and designated meeting venues in counties outside Dublin were accompanied by a parent and most tested in schools were observed by a teacher or special needs assistant. Following the pre-test assessment, students assigned to both the WWL and WWL-AR conditions were asked to use the application (AHA or WWL according to the condition they were assigned to) both at school and home with the support of an adult (teacher or parent/guardian depending on the intervention setting). The students, teachers, and parents were given a recommended schedule of work, ideally to be completed 5 days a week, and each session was to last approximately $15 \mathrm{~min}$ (Mangina, 2018). This was ample time to complete the programme over the project duration, if the schedule was followed as directed. Indeed, participants had access to their licence for a year, commencing in October 2018.

Teachers and parents who assisted their children during each session of the intervention were required to submit a rating of off-task behaviour, as described in Sect. 3.1. Additionally, they could use the monitoring interface functionalities for an ongoing check of children's progress and their engagement with the activities as it was continuously updated by the system. Students could use the application with the devices available at school and home and prior to the intervention a technical feasibility survey was completed by all teachers and parents to ensure that AHA platform was compatible with the hardware and software available at schools and family homes.

At the end of the pilot, separate reports were produced to provide feedback to teachers and parents about their children's outcomes and to inform the funding agency, and policy and decision makers about the pedagogical value of the AHA project.

\section{Preliminary findings of the AHA pilot}

The following sections report preliminary results of the AHA pilot obtained from analyses of data concerning children's performance on WWL questionnaires. Specifically, the aim of the present paper was the assessment of the difference between students assigned to the two intervention conditions (WWL-AR vs. WWL) in the performances on the questionnaires administered at the end of each WWL level. Consistently with existing literature showing a positive effect of AR solutions on educational outcomes, it was hypothesized that students assigned to WWL intervention enhanced with AR would show a better performance on the selected learning outcomes. 
Fig. 8 Interactive web-based tool designed for off-task behaviour rating

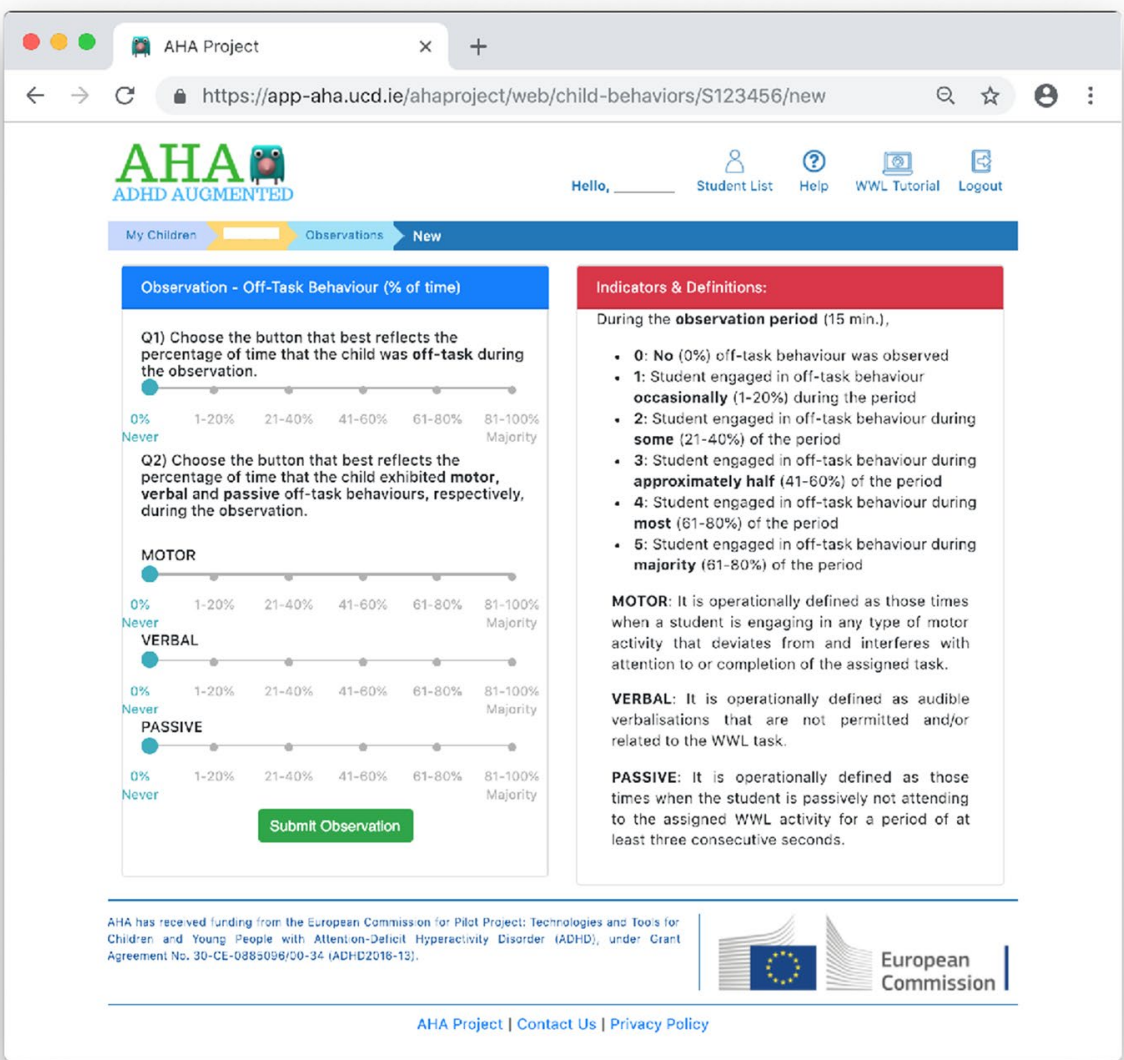

AHA Project I Contact Us | Privacy Policy

\section{Method}

\subsection{Participants}

As already pointed out, a total of 117 children participated in the pilot study. For the purposes of the present paper, data on the WWL questionnaires completed by children at each level of both the WWL and WWL-AR interventions were analysed. Table 2 summarizes the number of participants who completed each level questionnaire.

\subsection{Measures}

Learning outcome. As previously mentioned, only children's results on the 12 WWL questionnaires were considered and analysed as a measure of learning outcome for the purpose of the present paper. Specifically, measures of children's learning were derived from total scores obtained by participants on the questionnaires completed at the end of each level (or subsection of the level when required) of the WWL and WWL-AR intervention. Each questionnaire includes a set of 10 multiple-choice questions (the same in WWL and
WWL-AR) and total scores were derived as the total number of correct answers for each child.

\subsection{Statistical analysis}

Means and standard deviations, medians, and ranges were computed by group (WWL vs. WWL-AR) for the total scores in questionnaires completed by children. With regard to the aim of the study, a series of Mann-Whitney $U$ tests were used to assess the differences between the WWL and WWL-AR conditions, in pupils' performances on the questionnaires selected as outcome measures. More specifically, 10 Mann-Whitney $U$ tests were performed to compare between group children's average performance on questionnaires from level 1 to level 7, part 1. Mann-Whitney tests on questionnaires for level 7, part 2 and 3, were not run due to the overly small number of children who reached that level of the programme to enable them to complete the questionnaires. RStudio version 1.1.463 was used for statistical analyses. A p $<0.05$ was considered to be significant. 
Fig. 9 Facilities for data analytics
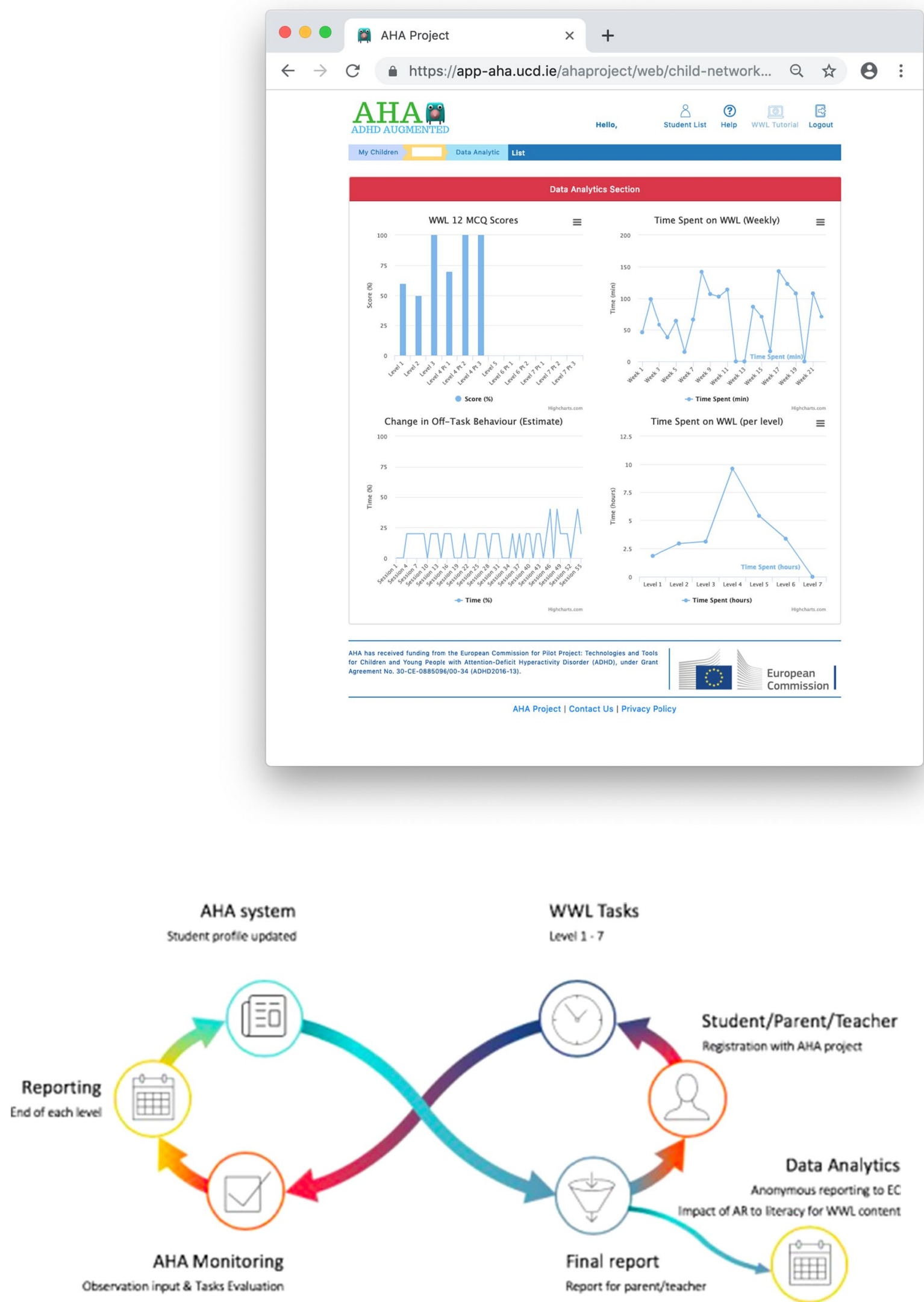

Fig. 10 Implementation of the AHA pilot 
Table 2 Descriptive statistics of questionnaires results by group and results of Mann-Whitney $U$ tests

\begin{tabular}{|c|c|c|c|c|}
\hline \multirow[t]{3}{*}{ Variable } & \multicolumn{4}{|c|}{ Intervention } \\
\hline & \multicolumn{2}{|c|}{ AR-WWL } & \multicolumn{2}{|c|}{ WWL } \\
\hline & $N$ & Female & $N$ & Female \\
\hline Level 1 questionnaire & 28 & 2 & 32 & 9 \\
\hline Level 2 questionnaire & 24 & 2 & 26 & 10 \\
\hline Level 3 questionnaire & 20 & 3 & 24 & 8 \\
\hline Level 4 part 1 questionnaire & 27 & 3 & 24 & 8 \\
\hline Level 4 part 2 questionnaire & 21 & 3 & 20 & 7 \\
\hline Level 4 part 3 questionnaire & 17 & 2 & 16 & 5 \\
\hline Level 5 questionnaire & 15 & 2 & 12 & 5 \\
\hline Level 6 part 1 questionnaire & 24 & 3 & 17 & 4 \\
\hline Level 6 part 2 questionnaire & 14 & 3 & 13 & 4 \\
\hline Level 7 part 1 questionnaire & 9 & 2 & 9 & 3 \\
\hline Level 7 part 2 questionnaire & 5 & 2 & 6 & 2 \\
\hline Level 7 part 3 questionnaire & 3 & 1 & 7 & 2 \\
\hline
\end{tabular}

$A R-W W L$ Augmented reality-wordsworth learning, $W W L$ Wordsworth learning, $N$ number of children who completed the questionnaire at the corresponding level

\section{Results}

A selection of relevant characteristics of the whole sample of 117 children participating in the pilot study is described in Table 1 (see Sect. 3); notably, nearly a half of participating children were reported to take ADHD-related medication
(54 students; 46\%). Table 3 shows descriptive statistics for questionnaires computed by type of intervention (WWL vs. WWL-AR); the table also includes the results of the 10 Mann-Whitney $U$ tests performed to compare the children's performance in the WWL questionnaires between the two interventions. Overall, these results show that children's performance was comparable across the two groups since no significant differences in average total scores on the administered questionnaires between the WWL and WWL-AR interventions were found.

\section{Discussion}

The main purpose of the current paper was to present preliminary findings on the effectiveness of integrating AR content into an effective web-based literacy programme in supporting the acquisition of literacy skills in a sample of children diagnosed with ADHD. The paper first provides an overall description of the ADHD-augmented (AHA) project, whose efforts the AHA system represents the result, with particular regard to the research design and methodology adopted to assess the incremental contribution of AR on children's literacy outcomes and engagement with the educational activities. Additionally, a more in-depth description of characteristics of participants in the project was contextually provided.

As described before, 117 pupils participated in the pilot and almost all of Irish origin. Most of them were male (80\%) and this is not surprising given the higher prevalence of
Table 3 Descriptive statistics of questionnaires results by intervention and results of Mann-Whitney $U$ tests

\begin{tabular}{|c|c|c|c|c|c|c|}
\hline \multirow[t]{3}{*}{ Variable } & \multicolumn{6}{|l|}{ Intervention } \\
\hline & \multicolumn{2}{|l|}{ AR-WWL } & \multicolumn{2}{|l|}{ WWL } & \multicolumn{2}{|c|}{$\begin{array}{l}\text { Mann-Whitney } \\
U \text { test }^{\mathrm{a}}\end{array}$} \\
\hline & $M(\mathrm{SD})$ & Range & $M(\mathrm{SD})$ & Range & $W$ & $p$ \\
\hline Level 1 questionnaire & $7.71(2.21)$ & $3-10$ & $7.78(1.56)$ & $4-10$ & 469 & 0.76 \\
\hline Level 2 questionnaire & $6.96(2.68)$ & $1-10$ & $5.92(2.83)$ & $1-10$ & 379 & 0.19 \\
\hline Level 3 questionnaire & $8.35(2.70)$ & $0-10$ & $8.50(1.82)$ & $2-10$ & 261 & 0.61 \\
\hline Level 4 part 1 questionnaire & $7.04(2.21)$ & $3-10$ & $6.79(2.47)$ & $0-10$ & 332 & 0.89 \\
\hline Level 4 part 2 questionnaire & $6.86(2.41)$ & $3-10$ & $6.75(2.86)$ & $1-10$ & 211.5 & 0.98 \\
\hline Level 4 part 3 questionnaire & $7.35(2.52)$ & $3-10$ & $6.69(2.15)$ & $2-10$ & 157.5 & 0.44 \\
\hline Level 5 questionnaire & $8.87(1.51)$ & $6-10$ & $9.42(1.00)$ & $7-10$ & 73.5 & 0.38 \\
\hline Level 6 part 1 questionnaire & $6.88(2.36)$ & $2-10$ & $6.82(2.53)$ & $3-10$ & 209.5 & 0.89 \\
\hline Level 6 part 2 questionnaire & $6.71(3.27)$ & $0-10$ & $5.77(2.92)$ & $1-10$ & 110.5 & 0.35 \\
\hline Level 7 part 1 questionnaire & $6.89(2.09)$ & $4-10$ & $6.89(1.76)$ & $4-10$ & 52.5 & 0.30 \\
\hline Level 7 part 2 questionnaire & $6.00(1.00)$ & $5-7$ & $7.17(2.14)$ & $5-10$ & - & - \\
\hline Level 7 part 3 questionnaire & $6.00(0.00)$ & $6-6$ & $6.71(1.89)$ & $4-10$ & - & - \\
\hline
\end{tabular}

$A R$-WWL Augmented reality-wordsworth learning, $W W L$ wordsworth learning, $N$ sample size, $M$ mean, $S D$ standard deviation, $W$ Wilcoxon statistic, $p$ p value

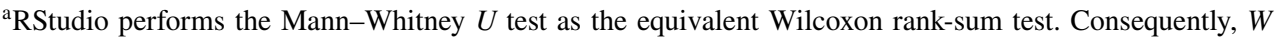
statistics (and corresponding $p$ values) are provided instead of $U$ statistics 
ADHD among boys especially when the disorder is recognized using administrative diagnoses (Sayal et al. 2018), as in the case of the AHA pilot. With regard to comorbidities, two-thirds of the total sample presented with dyslexia and language difficulties, while only one-third had speech difficulties. Notably, almost one-third of participants were diagnosed with an autistic spectrum disorder. The percentage of students presenting with dyslexia in the AHA pilot is higher than that reported in a relatively recent review according to which comorbidity rates for reading disorders fall in the range 11-52\% across studies (DuPaul et al. 2013). On the other hand, the percentage of children diagnosed with an autistic spectrum disorder in the pilot is roughly comparable to that reported in previous research (Berenguer-Forner et al. 2015; Leitner 2014). Notably, the majority of participants had access to both learning support and health-care provision in the form of psychological and psychiatric support and nearly a half of pupils were reported to take ADHD-related medication (54 students; 46\%). The amount of pharmacologically treated pupils is lower than that reported in a recent case note review summarizing results for medication use among young people accessing child and adolescent mental health services in Ireland (Tatlow-Golden et al. 2018).

With specific regard to the main aim of the current paper, we hypothesized that children undergoing WWL activities supported by the use of AR contents would show a higher performance than their WWL counterpart on the questionnaires administered at the completion of each level of the intervention. Specifically, it was hypothesized that AR contents would have promoted a better acquisition of literacy skills and rules given its potential beneficial impact on children's engagement with the educational activities. Results from statistical analysis did not provide evidence confirming this hypothesis; specifically, the current results showed that on average, children's performance on the questionnaires was similar across the two interventions. This finding suggests that the AR content, embedded into the WWL programme, did not exert an incremental positive effect on children's acquisition of literacy skills, as measured by the questionnaires selected as learning outcomes, compared to the WWL programme as usual. To the best of our knowledge, this is the first study that reports results on the incremental contribution of integrating AR content into an existing educational programme for enhancing the acquisition of reading and spelling skills in a sample of children diagnosed with ADHD. Most of the existing studies in the area of language education (Khoshnevisan, 2018) focused on teaching of a foreign language and assessed the effect of AR educational solutions on different learners' outcomes, such as completing a writing task, knowledge of grammar rules, vocabulary acquisition and retention, and motivation. Although the majority of these studies reported a positive impact of AR solutions on users' outcomes, they did not include a control condition for evaluation purposes and reported sample sizes were small. As a consequence, the comparison of the current findings with those of other studies in the same field is not straightforward. On the other hand, an AR system, similar to the AHA solution, has been developed to support non-English speaking children in the acquisition of English reading and spelling skills, mainly in terms of letter-sound associations (Fan et al. 2018). The system integrated AR into an existing educational tool and was designed to maintain children's attention focused on the learning tasks thus ideally enhancing their literacy skills development, but unfortunately the paper did not report any results on the evaluation of the system effectiveness.

Generally, research on the use of AR in educational settings has shown that AR systems promote learners' motivation, engagement, and memory retention of educational content thus providing a potential explanation of the incremental effect of AR solutions on academic achievement (e.g. Garzón et al. 2019; Saltan and Arslan 2017). Additionally, two recent studies suggested that embedding AR into problem-solving tasks and social and behavioural learning modules increased concentration in children with ADHD and reduced ADHD-related symptoms, such as inattention and impulsivity, in children diagnosed with autism spectrum disorder (Avila-Pesantez et al. 2018; Vahabzadeh et al. 2018). In this regard, the AHA research design included a measure of children's off-task behaviour in both the intervention conditions (WWL-AR and WWL as usual) to evaluate the potential effect of AR on their engagement with the proposed activities. However, the current results from the preliminary analysis did not address the selected behavioural outcome; subsequent data analyses will focus on the impact of AR on pupils' off-task behaviour.

It should be noted that the current analysis was performed on children's performance on the questionnaires as included in the WWL literacy programme; although results on these questionnaires can be considered as a measure of children's learning of reading and spelling skills, they are not standardized and validated measurement tools. Moreover, children did not complete all the questionnaires they were expected to fill in at the end of the levels of the interventions and missing responses probably affected the results of our analysis. These considerations suggest the need for caution in interpreting and generalizing the current findings. Subsequent analysis will be run on participating children's literacy outcomes as measured through the selected standardized measures of reading and spelling skills (see Sect. 3.1 for details); such analyses will potentially provide more reliable results on the effect of the AHA solution compared to both the WWL programme as usual and the control condition. Finally, a pretest/post-test research design was designed for the evaluation of the AHA system but no additional follow-up measurements were planned. Given that research has indicated longterm memory retention of educational content as a peculiar positive outcome of AR systems (Garzón et al. 2019), future 
studies should directly assess the impact of AR on memory retention, especially in the area of language education.

\section{Conclusions}

The AHA pilot project implemented an integration of existing and effective services and technologies resulting in a web-based application designed to address reading and spelling difficulties in children with ADHD. On the basis of evidence reported in the literature, the main assumption was that a set of AR objects embedded in an effective literacy programme may exert an additional beneficial impact on pupils' reading and spelling abilities via its effect in reducing students' levels of inattentive behaviour. The current results from the preliminary analysis did not provide support to this hypothesis showing that children enrolled in the WWL literacy programme with AR reported the same results on tasks assessing the acquisition of reading and spelling skills than children who used the WWL programme as usual. However, this finding should be considered with caution since the questionnaires used for evaluation purposes were not validated and standardized measures; second, only a limited number of children completed the questionnaires and this could have an impact on the power of the tests to detect a significant effect. A subsequent study will include data from all participants in the AHA project and focus as well on the impact of AR on both pupils' engagement with the task and literacy skills, as measured by validated and standardized tests; such analyses will potentially provide some confirmation to the hypothesis that AR may ameliorate learning outcomes while specifically increasing students' engagement with the proposed activities. Moreover, future studies in the area of language education should include larger sample sizes and more rigorous research designs to evaluate the effect of AR solutions.

The behavioural monitoring tool digitally incorporated in the AHA system was thought to facilitate and improve collaboration among those who take care of the child (e.g. parents, teachers, and speech and language therapists). Specifically, the monitoring tool can help child's significant adults support and monitor the learning process, improve the home-school communication by the identification of shared aims, and receive prompts about child's performance. Including a tool that addresses such aims is particularly relevant assuming that intervention strategies that increase significant adults' communication and awareness of their child's difficulties can strengthen the treatment success (Wright et al. 2015).

Acknowledgements We would also like to thank all the stakeholder involved in the project (parents, teachers, and students) for choosing to engage in the AHA pilot project and contribute to the development and improvement of innovative teaching and learning processes, through the use of the Information and Communication Technologies, and the enhancement of the Irish and International educational school system.

Funding This publication has been supported from European Commission under the funding for the project ADHD-Augmented (AHA) Grant Agreement No. 30-CE-0885096/00-34 (ADHD2016-13), under the Pilot Project: Technologies and Tools for Children and Young People with Attention Deficit Hyperactivity Disorder (ADHD). The opinions, findings and conclusions or recommendations expressed in this material are those of the authors and do not necessarily reflect the views of the European Commission.

Availability of data and material Data not available due to ethical restrictions: Although the students participated anonymously with a provided de-identified ID, due to the nature of this research, the data will not be shared publicly, so supporting data is not available.

Code availability Software application is not available due to ethical and commercial restrictions. The AHA platform has been adapted based on the open-source WHAAM project (https://github.com/gianl uca78/whaamproject), but the AHA platform project is not available due to the link with the data provided from the WordsWorth Learning licenced web-based literacy program.

\section{Compliance with ethical standards}

Conflict of interest The authors declare that they have no conflict of interest.

Ethics approval and consent to participate The only ethical dilemma within this pilot concerned the interactions with minors (students aged 9-12 years, attending 4th, 5th and 6th classes) at primary schools in Ireland and the collection of data in terms of the effect that AR has on reading, spelling and their behaviour. All participants in the project had to provide a consent form, based on the ethics' approval of the project. "Anonymity," "confidentiality," and "privacy" are three terms that were of high importance and adhered to within the AHA project and communicated to all participants. The conducted research included Ethics approval from UCD Research Ethics Committee and the project complies with UCD's Data Protection Policy and current Data Protection Legislation.

Open Access This article is licensed under a Creative Commons Attribution 4.0 International License, which permits use, sharing, adaptation, distribution and reproduction in any medium or format, as long as you give appropriate credit to the original author(s) and the source, provide a link to the Creative Commons licence, and indicate if changes were made. The images or other third party material in this article are included in the article's Creative Commons licence, unless indicated otherwise in a credit line to the material. If material is not included in the article's Creative Commons licence and your intended use is not permitted by statutory regulation or exceeds the permitted use, you will need to obtain permission directly from the copyright holder. To view a copy of this licence, visit http://creativecommons.org/licenses/by/4.0/. 


\section{References}

American Psychiatric Association (2013) Diagnostic and statistical manual of mental disorders, 5th edn. Author, Washington, DC

Avila-Pesantez D, Rivera LA, Vaca-Cardenas L, Aguayo S, Zuñiga L (2018) Towards the improvement of ADHD children through augmented reality serious games: Preliminary results. In: Proceedings of the 2018 IEEE global engineering education conference (EDUCON). IEEE, pp 843-848

Barkley RA (1997) ADHD and the nature of self-control. Guilford Press, New York

Berenguer-Forner C, Miranda-Casas A, Pastor-Cerezuela G, RoselloMiranda R (2015) Comorbidity of autism spectrum disorder and attention deficit with hyperactivity. A review study. Rev Neurol 60(S1):S37-S43

Billinghurst M, Duenser A (2012) Augmented reality in the classroom. Computer 45(7):56-63. https://doi.org/10.1109/MC.2012.111

Billinghurst M, Kato H, Poupyrev I (2001) The MagicBook: a transitional AR interface. Comput Graph 25(5):745-753. https://doi. org/10.1016/S0097-8493(01)00117-0

Carlson CL, Booth JE, Shin M, Canu WH (2002) Parent-, teacher-, and self-rated motivational styles in ADHD subtypes. J Learn Disabil 35(2):104-113. https://doi.org/10.1177/002221940203500202

Chafouleas SM, McDougal JL, Riley-Tillman TC, Panahon CJ, Hilt AM (2005) What do daily behavior report cards (DBRCs) measure? An initial comparison of DBRCs with direct observation for off-task behavior. Psychol Sch 42(6):669-676. https://doi. org/10.1002/pits.20102

Chafouleas SM, Riley-Tillman TC, Christ TJ (2009) Direct behavior rating (DBR) an emerging method for assessing social behavior within a tiered intervention system. Assess Eff Interv 34(4):195200. https://doi.org/10.1177/1534508409340391

Chiazzese G, Mangina E, Chifari A, Merlo G, Treacy R, Tosto C (2018) The AHA project: an evidence-based augmented reality intervention for the improvement of reading and spelling skills in children with ADHD. In: Proceedings of the 2018 international conference on games and learning alliance (GALA). Springer, Cham, pp 436-439. https://doi.org/10.1007/978-3-030-11548 $-7 \_44$

Daley D, Birchwood J (2010) ADHD and academic performance: why does ADHD impact on academic performance and what can be done to support ADHD children in the classroom? Child Care Health Dev 36(4):455-464. https://doi.org/10.111 $1 /$ j.1365-2214.2009.01046.x

Demaray MK, Jenkins LN (2011) Relations among academic enablers and academic achievement in children with and without high levels of parent-rated symptoms of inattention, impulsivity, and hyperactivity. Psychol Sch 48(6):573-586. https://doi. org/10.1002/pits.20578

DuPaul GJ, Gormley MJ, Laracy SD (2013) Comorbidity of LD and ADHD: implications of DSM-5 for assessment and treatment. J Learn Disabil 46(1):43-51. https://doi.org/10.1177/0022219412 464351

Fan M, Antle AN, Sarker S (2018) From tangible to augmented: designing a PhonoBlocks reading system using everyday technologies. In: Extended abstracts of the $2018 \mathrm{CHI}$ conference on human factors in computing systems. ACM, p LBW555. https:// doi.org/10.1145/3170427.3188459

Garzón J, Pavón J, Baldiris S (2019) Systematic review and metaanalysis of augmented reality in educational settings. Virtual Real. https://doi.org/10.1007/s10055-019-00379-9

Hoza B, Waschbusch DA, Owens JS, Pelham WE, Kipp H (2001) Academic task persistence of normally achieving ADHD and control boys: Selfevaluations, and attributions. J Consult Clin Psychol 69(2):271. https://doi.org/10.1037/0022-006X.69.2.271
Kazdin AE (2003) Research design in clinical psychology, 4th edn. Allyn \& Bacon, Needham Heights

Khoshnevisan B (2018) Augmented reality in language education: a systematic literature review. In: Proceedings of global conference on education and research (volume 2) (GLOCER) 59-74. ANAHEI Publishing, LLC, pp 59

Kofler MJ, Rapport MD, Bolden J, Sarver DE, Raiker JS (2010) ADHD and working memory: the impact of central executive deficits and exceeding storage/rehearsal capacity on observed inattentive behavior. J Abnorm Child Psychol 38(2):149-161. https://doi. org/10.1007/s 10802-009-9357-6

Leitner Y (2014) The co-occurrence of autism and attention deficit hyperactivity disorder in children-what do we know? Front Hum Neurosci. https://doi.org/10.3389/fnhum.2014.00268

Lin CY, Yu WJ, Chen WJ, Huang CW, Lin CC (2016) The effect of literacy learning via mobile augmented reality for the students with ADHD and reading disabilities. In: Proceedings of international conference on universal access in human-computer interaction. Springer, Cham, pp 103-111. https://doi.org/10.1007/978-3-31940238-3_11

Luman M, Oosterlaan J, Sergeant JA (2005) The impact of reinforcement contingencies on $\mathrm{AD} / \mathrm{HD}$ : a review and theoretical appraisal. Clin Psychol Rev 25(2):183-213. https://doi.org/10.1016/j. cpr.2004.11.001

Mangina E (2017) 3D learning objects for augmented/virtual reality educational ecosystems. In: Proceedings of the 23rd international conference on virtual system and multimedia (VSMM). IEEE, pp 1-6. https://doi.org/10.1109/VSMM.2017.8346266

Mangina E (ed) (2018) AHA: A pilot project for evaluating the effect of Augmented Reality in the reading and spelling skills for children with ADHD. Parent and Teacher Guide, Dublin. ISBN 978-1-910963-25-8

Mayer RE (2001) Multimedia learning. Cambridge University Press, New York. ISBN 978-0-521-78749-9

Neale MD (1997) Neale analysis of reading ability-revised. NFERNelson, Windsor

OECD Project Overcoming School Failure: Policies that Work National Report Ireland (2011). http://www.oecd.org/education/schoo 1/49624509.pdf. Accessed 22 Feb 2019

Ozdemir M, Sahin C, Arcagok S, Demir MK (2018) The effect of augmented reality applications in the learning process: a metaanalysis study. Eurasian J Educ Res 74:165-186. https://doi. org/10.14689/ejer.2018.74.9

Radu I (2014) Augmented reality in education: a meta-review and cross-media analysis. Pers Ubiquit Comput 18(6):1533-1543. https://doi.org/10.1007/s00779-013-0747-y

Saltan F, Arslan Ö (2017) The use of augmented reality in formal education: a scoping review. Eurasia J Math Sci Technol Educ 13(2):503-520. https://doi.org/10.12973/eurasia.2017.00628a

Sayal K, Prasad V, Daley D, Ford T, Coghill D (2018) ADHD in children and young people: prevalence, care pathways, and service provision. Lancet Psychiatry 5(2):175-186. https://doi. org/10.1016/S2215-0366(17)30167-0

Shapiro ES (1996) Academic skills problems workbook. Guilford Press, New York

Tatlow-Golden M, Gavin B, McNamara N, Singh S, Ford T, Paul M, Culle W, McNicholas F (2018) Transitioning from child and adolescent mental health services with attention-deficit hyperactivity disorder in Ireland: case note review. Early Interv Psychiatry 12(3):505-512. https://doi.org/10.1111/eip.12408

Treacy R (2017) Dyslexia unravelled: an Irish guide to a global problem. Orpen Press, Dublin

Vahabzadeh A, Keshav NU, Salisbury JP, Sahin NT (2018) Improvement of attention-deficit/hyperactivity disorder symptoms in school-aged children, adolescents, and young adults with autism via a digital smartglasses-based socioemotional coaching aid: 
short-term, uncontrolled pilot study. JMIR Mental Health 5:2. https://doi.org/10.2196/mental.9631

Vate-U-Lan P (2012) An augmented reality 3d pop-up book: the development of a multimedia project for English language teaching. In: Proceedings of IEEE international conference on multimedia and expo. IEEE, pp 890-895. https://doi.org/10.1109/ICME.2012.79

Vernon PE (2006) Graded word spelling test, revised and restandardized by Colin McCarty and Mary Crumpler. Hodder Education, London

Volpe RJ, DuPaul GJ, DiPerna JC, Jitendra AK, Lutz JG, Tresco K, Junod RV (2006) Attention deficit hyperactivity disorder and scholastic achievement: a model of mediation via academic enablers. Sch Psychol Rev 35(1):47

Wright N, Moldavsky M, Schneider J, Chakrabarti I, Coates J, Daley D, Kochhar P, Mills J, Sorour W, Sayal K (2015) Practitioner review: pathways to care for ADHD-a systematic review of barriers and facilitators. J Child Psychol Psychiatry 56(6):598-617. https://doi. org/10.1111/jcpp. 12398

Zhou F, Duh HBL, Billinghurst M. (2008) Trends in augmented reality tracking, interaction and display: a review of ten years of ISMAR. In: Proceedings of the 7th IEEE/ACM international symposium on mixed and augmented reality. IEEE Computer Society, pp 193-202. https://doi.org/10.1109/ISMAR.2008.4637362

Publisher's Note Springer Nature remains neutral with regard to jurisdictional claims in published maps and institutional affiliations. 